\title{
One Word, Two Definitions: A Comparison of Word Definitional Skills between Monolingual and Bilingual Students
}

\author{
Chrysoula Dourou* \\ Department of Greek Philology, Democritus University of Thrace \\ University Campus, 69100 Komotini, Greece \\ E-mail: chysadr@yahoo.com \\ Ifigeneia Dosi \\ Department of Greek Philology, Democritus University of Thrace \\ University Campus, 69100 Komotini, Greece \\ E-mail: idosi@helit.duth.gr
}

This research is co-financed by Greece and the European Union (European Social Fund- ESF) through the Operational Programme "Human Resources Development, Education and Lifelong Learning» in the context of the project "Reinforcement of Postdoctoral Researchers - 2nd Cycle" (MIS-5033021), implemented by the State Scholarships Foundation (IKY). We are thankful to the children that participated in this study and, also, to their parents for the support. The authors also thank the editors and the reviewers for their useful and insightful comments for the improvement of the manuscript.

\section{Abstract}

The purpose of this study was to expand the current literature on word definitions, to empirically investigate (a) the definitional skills, (b) the effect of grammatical category of the word and (c) the preferred definition types produced by Greek monolingual students and Turkish-Greek bilingual students of different levels of education. Previous research has shown that bilinguals produce better definitions than their monolingual peers due to their enhanced metalinguistic abilities. To date, no studies have compared the definitional skills considering word grammatical categories in bilingual students of different levels of education. To this end, 158 students -79 monolingual speakers of Greek and 79 bilingual speakers (L1 Turkish, L2 Greek) - were tested and were asked to define 16 words (8 nouns, 4 verbs, and 4 adjectives), orally. Definitions were scored on a five-point scale along a continuum that reflects the developmental path of the definitions. The findings indicated that monolinguals outperformed bilinguals in respect to the content of definitions in all grammatical categories, regardless of their level of education. Nevertheless, in form, the differences between the groups disappeared in senior high school. Bilingual students catch up their monolingual peers, conceivably, due to their enhanced metalinguistic abilities. The finding further supports that content of definitions is a more sensitive indicator. Within group comparisons have shown that the production of formal definitions exhibits in junior high school, while it takes more time for this pattern to emerge in bilinguals (i.e. in senior high school). Nouns were better defined than verbs and adjectives. Verbs and adjectives did not differ in upper elementary school students; however, a difference arose in junior high school, i.e. more formal definitions were used in adjectives compared to verbs, proving that verbs are more abstract and, thus, difficult to be defined. All in all, the present study offers useful insights about the development of word definitional skills considering word grammatical categories in bilingual and monolingual students of different levels of education and discusses the outcomes in the light of educational practices.

Keywords: definitional skills, monolingual students, bilingual students, grammatical categories

DOI: $10.7176 / \mathrm{JEP} / 12-8-01$

Publication date:March $31^{\text {st }} 2021$

\section{Introduction}

The nature and characteristics of definitions have been discussed in various ways. Previous research focused mainly on the ability of native speakers to define words (Watson, 1985; Benelli et al., 1988; Benelli et al., 2006; Marinellie, 2010; Gavriilidou, 2015; Dourou, 2019). According to previous studies, definitional skills process gradually and start from early childhood, where speakers provide mostly erroneous or functional definitions, and continues into adulthood where more formal definitions are used. After the age of 12, definitions are not so descriptive and functional, but definitional skills still need time to develop (Dourou, 2019; Dourou, Gavriilidou \& Markos, 2020). The development of word definitions is, also, a practice that is reinforced in the classroom by means of feedback, instructions (Marinellie, 2010; González et al., 2014; Malekian et al., 2014). In addition, vocabulary enhancement and organization may have an impact on the development of definitional skills (Dosi, 2020; Dosi, Gavriilidou \& Dourou, in press). It is also a process that is enhanced through various activities (writing paragraphs, telling stories, answering comprehension questions, language productions) that take place in the school environment.

There are many factors that influence the formulation of definitions. Thus, the grammatical category of the 
words, i.e. nouns, verbs, adjectives (Markowitz \& Franz, 1988; McGhee-Bidlack, 1991; Nippold et al., 1999; Johnson \& Anglin, 1995; Gavriilidou, 2015; Colombo et al., 2016; Dourou, 2019), the morphological structure (Dourou, 2019) and the level of abstraction (McGhee-Bidlack, 1991; Johnson \& Anglin, 1995; Sadoski et al., 1997; Nippold et al., 1999; Gavriilidou, 2015) affects the way that children define words. In addition, however, there are some other factors that affect the production of definitions. Age is a factor that is examined by many researchers; thus, definitional skills were investigated in preschoolers (Nippold et al., 1999; Benelli et al., 2006; Gavriilidou, 2015; Dourou, 2020), in elementary students (Benelli et al., 1988; Snow, 1990; McGhee-Bidlack, 1991; Johnson \& Anglin, 1995; Kurland \& Snow, 1997; Dourou, 2019), in senior and high school students (Caramelli, Borghi \& Setti, 2006; Dourou, 2019), but also, in adults (Nippold et al., 1999; Marinellie \& Johnson, 2003; Benelli et al., 2006; Chan \& Marinellie, 2007; Dourou 2020). Other factors that are examined in relation to the development of definitional skills are gender (Benelli et al., 2006; Dourou, 2019; Dourou, Gavriilidou \& Markos, 2020), education level and career orientation (Walker, 2001; Benelli et al., 2005; Benelli, Belacchi, Gini \& Lucangeli, 2006; Dourou et al., 2020).

Definitional skills of bilingual speakers are less examined. Previous studies have shown that bilinguals provided better definitions possibly due to their increased metalinguistic abilities (Snow et al., 1991; Lee, 2005; Kang, 2013). Differences were mainly observed in content (Kang, 2013). The role of language proficiency was not emerged as an important factor by all studies (Ordonez et al., 2002; El Euch \& De Koninck, 2006; Pham et al., 2018), suggesting that knowing a word does not necessarily mean knowing how to define it. However, studies in monolingual children have shown that vocabulary knowledge correlate with the development of definitions (Wehren et al., 1981; Marinellie \& Johnson, 2002, Dosi \& Gavriilidou, 2020), but only in nouns and adjectives, suggesting that due to the complexity of the verbs, more time is needed for the link to emerge (Dosi et al., in press). Nevertheless, Malakoff (1988) claimed that performance on language tasks was better in the school language even for students whose proficiency in that language was limited. Moreover, previous studies (Snow, 1990; Snow et al., 1991) found that bilingual children provided better definitions in the language of formal instruction or in the language of schooling; highlighting the pivotal role of schooling. Similar to the development of definitions in monolingual speakers, age also found to play a crucial role in the development of dentitions in bilingual speakers, since they enhance with age. Snow (1990) study on 137 bilingual children (aged seven to eleven) showed that the use of formal definitions strongly correlated with children's age. Moreover, a part of the results (data on nine children) suggested that definitional skill may be transferred from the stronger to the weaker language if a high level of L2 proficiency is attained and if the metalinguistic ability is developed; confirming Cummins' $(1976,1979)$ Interdependence Theory and Common Underlying Proficiency Model, which claim that bilingual speakers transfer skills across languages. In the same vein, in her recent study Charkova (2005) compared 120 Bulgarian students (mean age 10.4), 40 monolinguals, 40 bilinguals (L1 Bulgarian, L2 English) and 40 trilinguals (L1 Bulgarian, L2 English, L3 Russian) in their word definition performance in L1. The purpose of her study was to find out if learning foreign languages facilitates children's translingual ability to define words. The outcomes of her study showed that bilingual and trilingual children performed much better than monolinguals. It has also been found that the ability to translate words from L1 to L2 / L3 can be more easily achieved between languages with the same typology (Bulgarian and Russian) than between typologically distant languages (Bulgarian/Russian and English) (Charkova 2005). El Euch (2007) studied the quality of written nominal definitions given by 230 students (mean age 17.1) in three languages: Arabic(L1), French (L2) and English (L3). Her results showed that language proficiency plays a role in the quality of definitions and, also, indicated that the production of a formal definition is not only a matter of language skills, but it also requires metalinguistic and academic skills (El Euch \& De Koninck, 2006). By contrast, Kang (2013) studied the word definitional skills of 70 Korean-English bilingual children, aged 5 to 6 years, whose first language was Korean. The results designated that the participants of his study provided better definitions in their home language than in their school language.

To date, to our knowledge, few studies compared monolingual with bilingual individuals in their ability to define words and no studies have examined the role of grammatical categories in the development of definitions.

\section{Research questions and hypotheses}

Addressing the gaps in literature, the present study aims to provide new insights about variation in definitional skills of Greek monolingual students and Turkish-Greek bilingual students, considering factors such as level of education (upper elementary students, junior and senior high school students), and the grammatical category of the word (noun, adjective, verb).

The present study addressed three interrelated questions:

1. Do the definitional skills of monolingual and bilingual students of different levels of education differ in content and form?

Based on previous literature (Snow et al., 1991; Lee, 2005; Kang, 2013), we expected that bilingual students would produce better definitions in form, since form is related to metalinguistic skills (Bialystok, 1986). In content, we hypothesized that bilinguals' performance would be lower than monolinguals, due to their lower 
language proficiency in Greek.

2. Do grammatical categories affect the definitions of monolingual and bilingual students of different levels of education in the same way?

Our second hypothesis was that monolinguals would outperform bilinguals in all grammatical categories, due to their increased vocabulary knowledge (Marinellie \& Johnson, 2002). In addition, we expected that nouns would be better defined compared to adjectives and verbs (as previous studies suggested, Johnson \& Anglin, 1995; Gavriilidou, 2011, 2015; Dourou, 2019). In addition, we expected that junior and senior high school students would outperform upper elementary school students, regardless of the language group (monolinguals and bilinguals; cf. Benelli et al., 1988; Snow et al., 1991; Johnson \& Anglin, 1995; Nippold, 1995; Dourou, 2019).

3. Do monolingual and bilingual students from different levels of education use different types of definitions per grammatical category?

Based on previous literature (Johnson \& Anglin, 1995; Skwarchuk \& Anglin, 1997; Marinellie \& Johnson, 2003; Gavriilidou, 2015), we expected that the types of word definitions (in content and form) provided by our sample would reflect the developmental path of the definitions and that junior and senior high school students would provide more formal definitions (in content and form) in comparison to upper elementary students. In addition, we expected that bilingual students would produce high-level responses definitions in form, particularly in junior and senior high school. In content, we hypothesized that bilinguals' performance would be lower (low- or mid-level responses) than monolinguals (high-level responses), due to their lower language proficiency in Greek.

\section{Methods}

\subsection{Participants}

In this study 158 students participated ( 79 monolingual Greek monolingual speakers and 79 sequential TurkishGreek bilingual speakers, dominant in Turkish), who were recruited from public schools in Thrace, Greece. The bilingual students attended public bilingual schools in Thrace. The age range of both groups was 9-17 years (mean age: 13.2 years; SD: 2.2 years). The first group consisted of 56 elementary students ( 28 monolinguals and 28 bilinguals; aged 9-12 years; mean age: 10.9 years; SD: 1.0 year). The second group consisted of 38 junior high school students (19 monolinguals and 19 bilinguals; aged 12-14 years; mean age: 13 years; SD: 0.7 years) and the third group consisted of 64 students senior high school students (32 monolinguals and 32 bilinguals; aged 15-17 years; mean age: 15.6 years; SD: 0.9 years).

\subsection{Stimuli and procedures}

For the purpose of this study, the methodology adopted were similar to those used in the study of Marinellie \& Johnson $(2002,2004)$ and previously adapted in Greek and applied in Gavriilidou (2015), Dourou (2019), Dourou et al. (2020), Dosi and Gavriilidou (2020). The task included 16 items. Eight of these were nouns, four were adjectives and four were verbs, as depicted in Table 1. More specifically, ten of the words have been selected from school coursebooks and the other six from the study of Gavriilidou (2015).

Table 1. Definitional task items grouped per grammatical categories

\begin{tabular}{|c|c|}
\hline Grammatical categories & Task items \\
\hline \multirow{8}{*}{ Nouns } & milo 'apple' \\
\hline & poðilato 'bike' \\
\hline & taksiði 'trip' \\
\hline & erotisi 'question' \\
\hline & tiropita'cheese pie' \\
\hline & maçeropiruno 'cutlery' \\
\hline & i.Kovasilema 'sunset' \\
\hline & makrozoia 'longevity' \\
\hline \multirow{4}{*}{ Verbs } & Sjavazo 'read' \\
\hline & xorevo 'dance' \\
\hline & aniroklino 'open and close' \\
\hline & 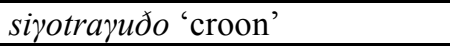 \\
\hline \multirow{4}{*}{ Adjectives } & astios 'funny' \\
\hline & eksipnos 'smart' \\
\hline & aspromavros 'black and white' \\
\hline & ylikoksinos 'sweet and sour' \\
\hline
\end{tabular}

The researcher just asked the participant "what does X mean?", without showing any picture or object or without any further prompt. Participant's response was audio-taped and transcribed afterwards. The questions were 
asked orally without the presence of other individuals during this process, in order to avoid any literacy effects.

The coding was based on Marinellie and Johnson $(2002,2004)$. Participants' answers were scored for both content and form on a five-point scale. For content-scoring, if the participant pointed the defined object or used gestures in describing the word, they received 0-point. In accordance with previous literature, as Low-level responses (see Table 2) were Function, Description, Example, and Association (1 point). Mid-level responses (see Table 2) were Class-Nonspecific, Class-Specific, and Synonym (2-3 points), while High-level responses included Combination (any combination of Function, Descriptive, Concrete, and Association, or Class-Nonspecific), and Formal (combination of Class-Specific or Synonym and at least one specifying attribute such as Function, Concrete, etc.; received 4-5 points).

Table 2. Examples of scoring the content of definitions

\begin{tabular}{|c|c|c|c|c|}
\hline Content category & Noun (question) & Adjective (funny) & Verb (read) & Points \\
\hline Non-verbal & \multicolumn{3}{|c|}{ they show the thing, they use gestures or they give a wrong answer } & 0 \\
\hline $\begin{array}{l}\text { Function/ } \\
\text { Description/ Example/ } \\
\text { Association }\end{array}$ & "what's the time?" & "my dad" & "book" & 1 \\
\hline Class non-specific & "a word" & "video" & "describe" & 2 \\
\hline $\begin{array}{lll}\text { Class } & \text { specific } & \text { or } \\
\text { synonym }\end{array}$ & "inquiry" & "amusing" & "study" & 3 \\
\hline Combination & $\begin{array}{l}\text { "a phrase with a } \\
\text { question mark at } \\
\text { the end" }\end{array}$ & $\begin{array}{l}\text { "someone who has } \\
\text { humor" }\end{array}$ & "to study a book" & 4 \\
\hline Formal & $\begin{array}{l}\text { "a clause that asks } \\
\text { for an answer" }\end{array}$ & $\begin{array}{l}\text { "causing laughter or } \\
\text { amusement" }\end{array}$ & $\begin{array}{l}\text { "to look at the words and } \\
\text { understand their meaning" }\end{array}$ & 5 \\
\hline
\end{tabular}

Form scoring for words is displayed in Table 3. Participants received 0 points if they provided non-verbally definitions (see Table 3). Low-level responses (see Table 3) included the use of One Word (but not the superordinate category) and a determiner (1 point). Mid-level responses deemed a Verb Phrase and the words "something/thing" along with a referential phrase (2-3 points). High-level responses (4-5 points; see Table 3) were Partial Aristotelian/formal definitions with the superordinate category or an infinitive or verb phrase; in addition, Aristotelian/ formal definitions were included. Aristotelian/ formal definitions, finally, contained the Partial Aristotelian + a second infinitive or a nonfinite clause or a finite adverbial clause, or a prepositional phrase. Table 3. Examples of scoring the form of definitions

\begin{tabular}{|c|c|c|c|c|}
\hline Form category & Noun (question) & Adjective (funny) & Verb (read) & Points \\
\hline Non-verbal & \multicolumn{3}{|c|}{ they show the thing, they use gestures or they give an error answer } & 0 \\
\hline 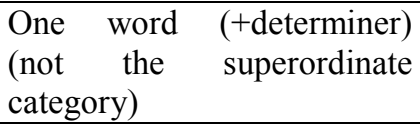 & "a word" & "smile" & "a text" & 1 \\
\hline Verb phrase & "I have queries" & "we laugh" & "I read a novel" & 2 \\
\hline $\begin{array}{l}\text { Transitional } \\
\text { ("Something"or "thing" + } \\
\text { referential sentence) }\end{array}$ & $\begin{array}{l}\text { "something that needs } \\
\text { to be answered" }\end{array}$ & $\begin{array}{l}\text { "something that } \\
\text { causes laughter" }\end{array}$ & $\begin{array}{l}\text { "something that } \\
\text { relaxes us" }\end{array}$ & 3 \\
\hline $\begin{array}{lr}\text { Partially } & \\
\text { Aristotelian/ } & \text { formal } \\
\text { definitions } & \text { (superordinate } \\
\text { category) } & \\
\end{array}$ & $\begin{array}{l}\text { "a phrase with a } \\
\text { punctuation mark at } \\
\text { the end" }\end{array}$ & $\begin{array}{l}\text { "the person who } \\
\text { says jokes" }\end{array}$ & $\begin{array}{l}\text { "to recognize or } \\
\text { interpret by going } \\
\text { through a text" }\end{array}$ & 4 \\
\hline Formal & $\begin{array}{l}\text { "a sentence worded or } \\
\text { expressed so as to } \\
\text { elicit information" }\end{array}$ & $\begin{array}{l}\text { "somebody who has } \\
\text { the sense of humor } \\
\text { and makes people } \\
\text { laugh" }\end{array}$ & $\begin{array}{l}\text { "to look at words and } \\
\text { understand their } \\
\text { meaning" }\end{array}$ & 5 \\
\hline
\end{tabular}

In either content or form, the highest possible form score for any participant was 80 points (16 words per participant, with a maximum of 5 points per word).

\subsection{Reliability}

Inter-judge reliability of content coding was evaluated for all responses given by 34 subjects (in total 2176 definitions). Any response was coded identically by two evaluators. The evaluators were the first author and the second author. Both evaluators had a set of acceptable responses. The assessment was a blind making assessment. The percentage of agreement was determined by dividing the number of responses coded identically by the total number of coded definitions. The inter-judge agreement for content was $98.4 \%$. Inter-judge reliability of form 
coding was evaluated in a similar way. The interjudge agreement for form was $97.7 \%$. To resolve the existing differences in evaluation, the first author made the final coding decisions and assigned the mean score to participants' responses.

\subsection{Data analyses}

In order to test our first research question, we conducted two two-way ANOVAs with dependent variables content and form, respectively, and as fixed factors were set language group (monolinguals, bilinguals) and education level (upper elementary school students, junior high school students and senior high school students).

For the investigation of our second research question, we run two two-way repeated measures ANOVA, for content and for form, setting as with-in subject variables the three grammatical categories (nouns, verbs and adjectives) and as between subject factors group and level of education.

In order to answer our last research question, we preformed qualitative analysis and thus the frequencies of definitional types (low-level responses, mid-level responses and high-level responses) in both content and form per language and education level group were reported.

\section{Results}

A two-way ANOVA was conducted that examined the effect of language group and education level on the content of definitions. There was a statistically significant interaction between the effects of language group and education level on the content of definitions $\left(F(2,158)=3.871, p=.023, \eta^{2}=.048\right)$. Simple main effects analysis showed that language group affect the development of definitions $\left(F(1,152)=51.882, p<.001, \eta^{2}=.203\right)$. Hence, monolinguals produced better definitions in terms of content than bilinguals in all education levels (in upper elementary and junior high school: $p<.001$, for both comparisons; and in senior high school: $p=.048$ ).

Education level affects both monolingual $(F(2,152)=9.864, p<.001)$ and bilingual groups $(F(2,152)=$ $13.867, p<.001)$, albeit in a different fashion. Pairwise comparisons Bonferroni showed that in the monolingual group the improvement in definitions emerges in junior high school (upper elementary students vs. junior and senior high school students $p<.001$, for both comparisons; whereas junior and senior high school students: $p=.605$ ), while for the bilingual group it takes more time for the enhancement to manifest and it emerges in senior high school (senior high school students vs. upper elementary and junior high students $p<.001$ and $p=.001$, respectively; while upper elementary and junior high school students: $p=.270$ ).

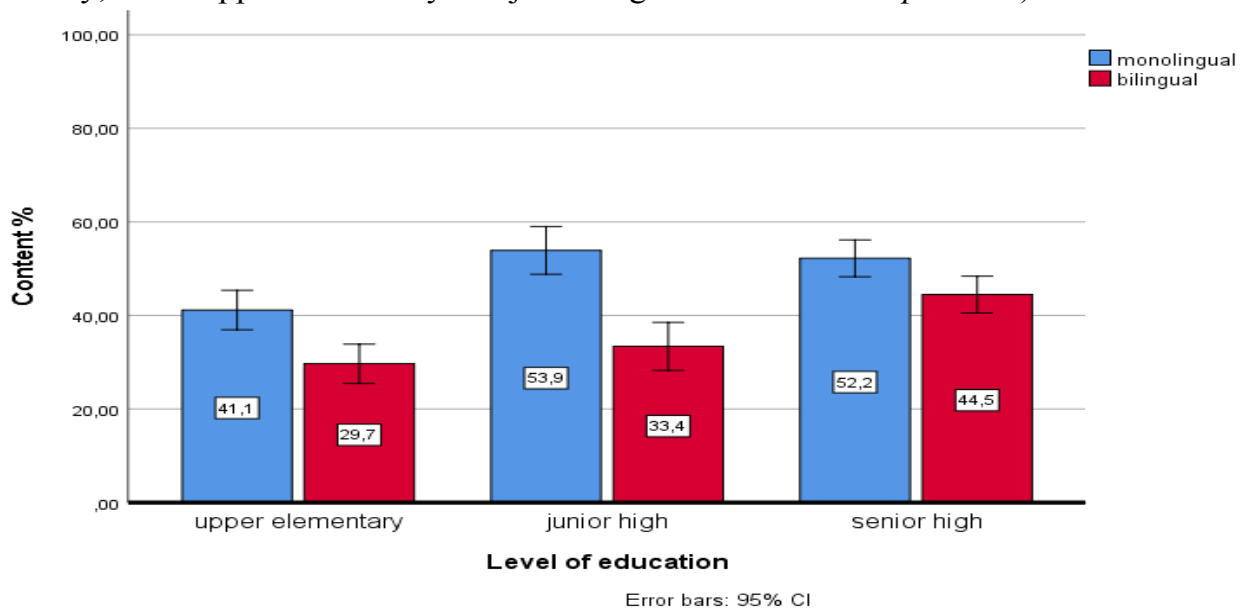

Figure 1. Monolinguals' and bilinguals' overall scores per age group in content

Similarly, for form, a two-way ANOVA was conducted that examined the effect of language group and education level on the form of definitions. There was a statistically significant interaction between the effects of language group and education level on the form of definitions $\left(F(2,158)=4.065, p=.019, \eta^{2}=.051\right)$. Simple main effects analysis showed that language group affect the development of definitions $(F(1,152)=$ $44.958, p<.001, \eta^{2}=.228$ ). Monolinguals produced better definitions in terms of form than bilinguals in upper elementary and in junior high school ( $p<.001$, for both analyses) but in senior high school the difference between the groups disappears $(p=.122)$.

Education level affects both monolingual $\left(F(2,152)=4.215, p=.017, \eta^{2}=.058\right)$ and bilingual groups $(F(2$, $\left.152)=7.265, p=.001 \eta^{2}=.092\right)$, albeit in a different way. Pairwise comparisons Bonferroni showed that in the monolingual group, junior high school students outperform only upper elementary students $(p=.004)$, while no other differences were found (junior vs. senior high school students $p=.130$; upper elementary and senior high school students: $p=.109$ ). In the bilingual group the enhancement in form appears in senior high school (senior high school students vs. upper elementary students $p<.001$; senior vs. junior high school students $p=.014$; while 
upper elementary and junior high school students: $p=.390)$.

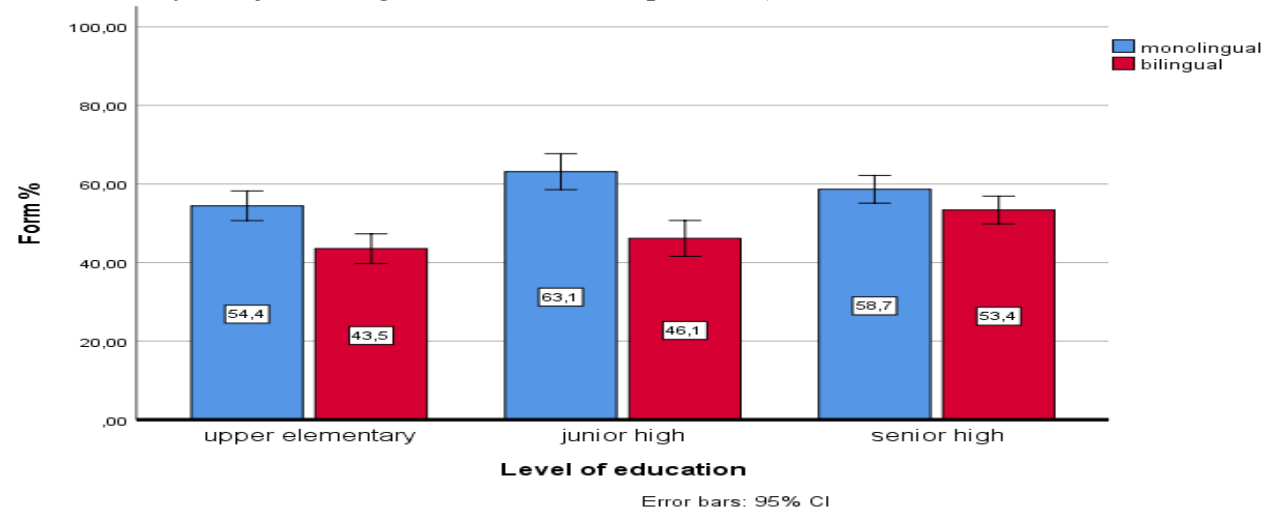

Figure 2. Monolinguals' and bilinguals' overall scores per age group in form

Answering our second research question, we performed repeated measures ANOVA. The results in content (cf. Figure 3 ) have shown that there was a statistically significant interaction between the effects of language group and grammatical categories $\left(F(2,304)=10.200, p<.001, \eta^{2}=.063\right)$ and another interaction between the effects of education level and grammatical categories $\left(F(4,304)=3.396, p=.010, \eta^{2}=.043\right)$, suggesting that the groups performed differently; while but no interaction between the effects of language group, education level and grammatical categories $\left(F(4,304)=.991, p=.412, \eta^{2}=.013\right)$. Simple main effects analysis showed that language group and education level affect the development of definitions $\left(F(1,152)=41.753, p<.001, \eta^{2}=.215 ; F(1,152)\right.$ $=21.439, p<.001, \eta^{2}=.220$; respectively).

In content, in upper elementary school, monolinguals outperformed bilinguals in nouns and verbs $(p<.001$ and $p=.005$, respectively), but not in adjectives $(p=.381)$. In junior high school, monolinguals exhibited higher performance in all grammatical categories in comparison to bilinguals $(p<.001$, for all comparisons). In senior high school, the only difference that remained was in nouns $(p=.008)$, but not in verbs and adjectives $(p=.423$; $p=.316$; respectively). Pairwise comparisons have shown that nouns were better defined than verbs and adjectives by both groups across the three education levels ( $p<.001$, for all comparisons); while, adjectives and verbs did not differ in upper elementary school (monolinguals: $p=.585$; bilinguals: $p=.107$ ), but a difference emerged from junior high school and onwards (junior high school, monolinguals: $p=.039$, bilinguals: $p=.020$; senior high school, monolinguals: $p=.001$, bilinguals: $p=.002$ ).

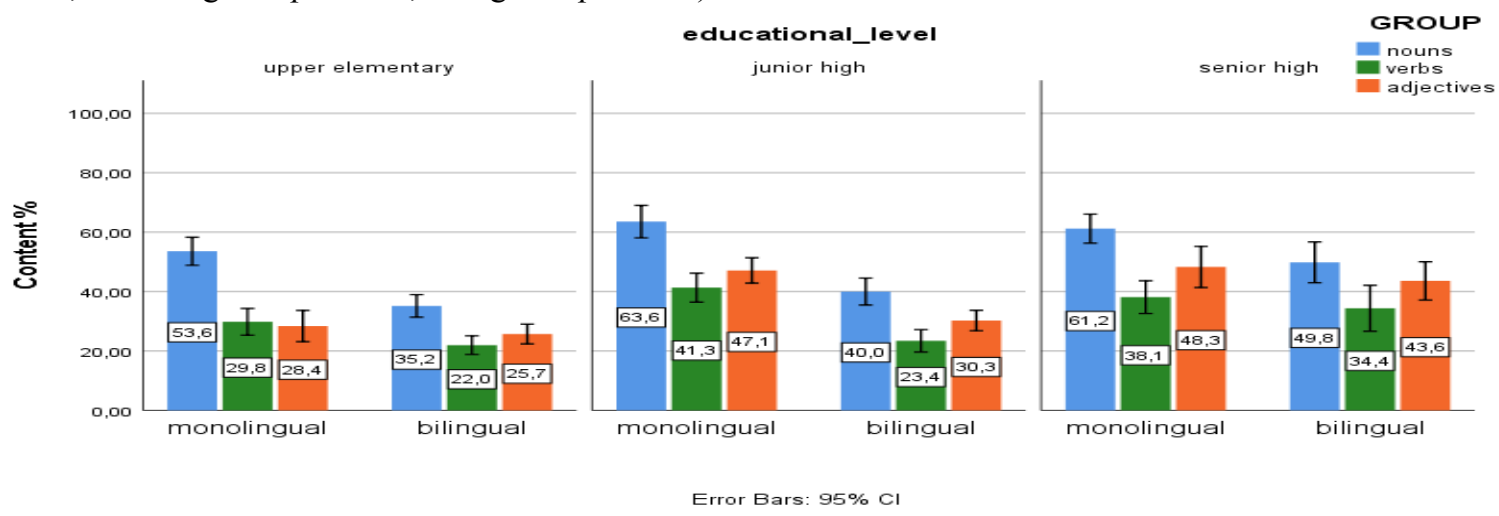

Figure 3. Groups' scores (in content) regarding grammatical categories.

The results in form (cf. Figure 4) have revealed that there was a statistically significant interaction between the effect of language group and grammatical categories $\left(F(2,304)=9.035, p<.001, \eta^{2}=.056\right)$; while but no interactions were found between education level and grammatical categories $\left(F(4,304)=.891, p=.469, \eta^{2}=.012\right)$, and between the effects of language group, education level and grammatical categories $(F(4,304)=.991, p=.412$, $\left.\eta^{2}=.013\right)$. Simple main effects analysis showed that language group and education level affect the development of definitions $\left(F(1,152)=38.642, p<.001, \eta^{2}=.203 ; F(1,152)=9.279, p<.001, \eta^{2}=.109\right.$; respectively).

In form, in upper elementary school, monolinguals outperformed bilinguals in nouns and verbs $(p=.001$ and $p=.002$, respectively), but not in adjectives $(p=.097)$. In junior high school, monolinguals exhibited higher performance in all grammatical categories in comparison to bilinguals ( $p<.001$, for all comparisons). In senior high school, the only difference that remained was in nouns $(p=.011)$, but not in verbs and adjectives $(p=.902$; $p=.681$; respectively). Pairwise comparisons have shown that in monolinguals nouns were better defined than verbs and adjectives across all the three education levels ( $p<.001$, for all comparisons). Interestingly, in bilinguals, the form in nouns did not differ from that in adjectives in all education levels (upper elementary school: $p=.174$; 
junior high school: $p=.084$; senior high school: $p=.314)$. Adjectives and verbs did not differ in monolingual upper elementary students $(p=.199)$, but the two categories differed in bilingual upper elementary students ( $p$ $=.045)$. Differences between adjectives and verbs emerged in junior high school and onwards for both groups (junior high school, monolinguals: $p=.026$, bilinguals: $p=.004$; senior high school, monolinguals: $p=.002$, bilinguals: $p=.005)$.

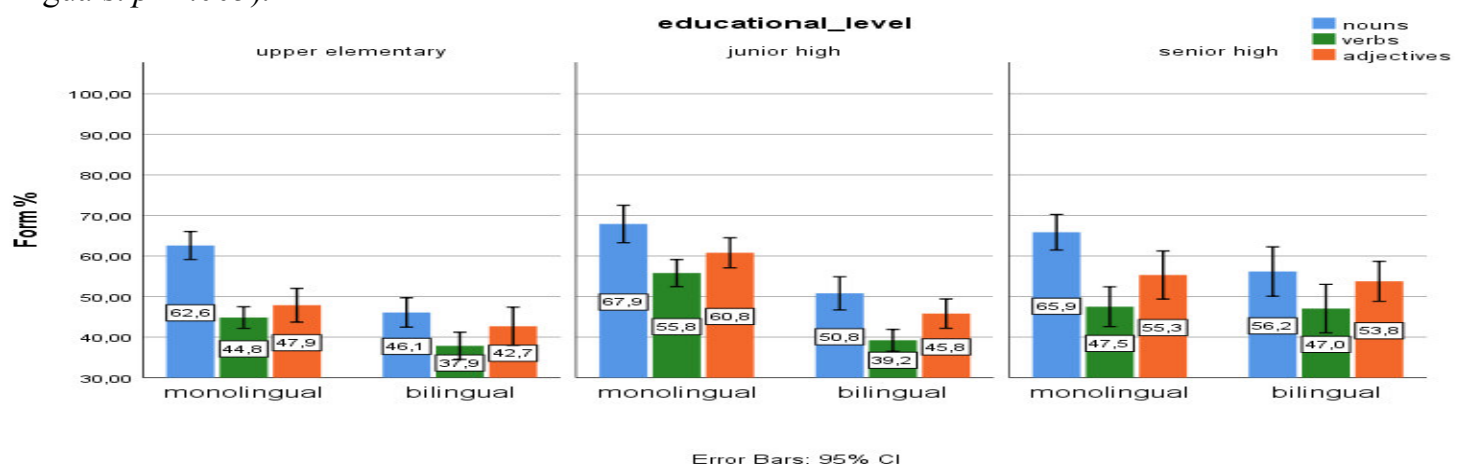

Figure 4. Groups' scores (in form) regarding grammatical categories.

In order to answer our last research question, we calculated the frequencies of the definitional types in both content and form, in order to observe whether the use of low-, mid- or high-level responses changes across the different levels of education.

When it comes to content, as Table 4 indicates, most of the participants provided low-level responses (i.e. functional definitions), particularly in verbs and adjectives. However, in nouns, all monolingual students and only bilingual high school students used high-level responses (i.e. combination). At this point, we should note that monolingual students of upper elementary school show great divergence among their answers; in other words, they either use low-level responses $(36.6 \%)$ or high-level-responses $(40.6 \%)$.

In form (see Table 5), a similar pattern was observed, the majority of the participants used low-level responses (i.e. verb phrase), particularly in verbs and adjectives. Nevertheless, we should note that great divergence was detected in adjectives in junior high school monolingual students; thus, they produced either low-level responses $(27.6 \%)$, or mid-level responses $(40.8 \%)$ or high-level responses $(31.6 \%)$. In nouns, the monolingual speakers of all groups gave high-level responses (i.e. partially Aristotelian/Formal definitions), while the same strategy was observed only in bilingual high school students.

Table 4. Definitional types in different categories in content per group ${ }^{1}$

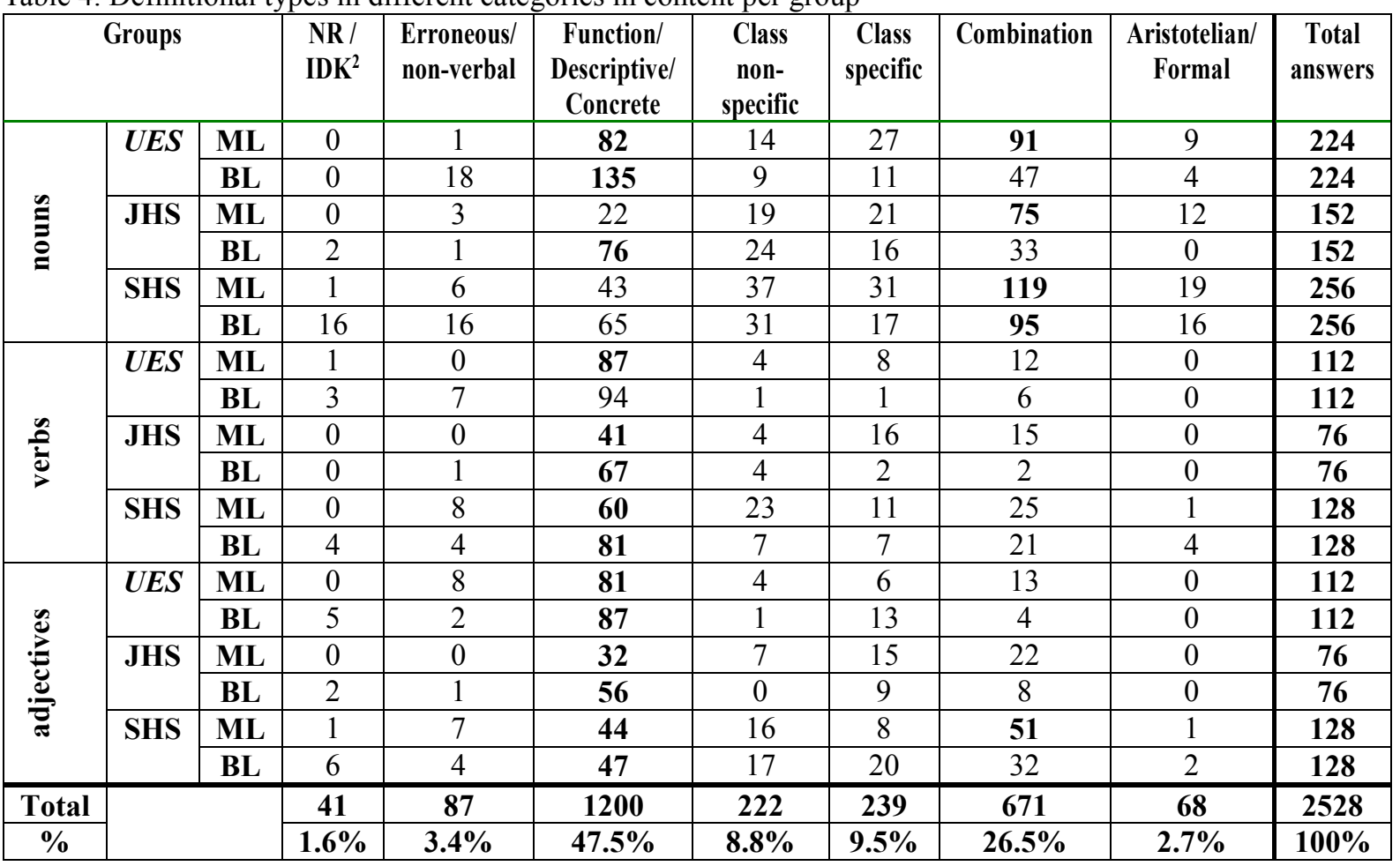

\footnotetext{
${ }^{1}$ In bold are the sum and the most frequent answers (both in Table 4 and Table 5).

${ }^{2}$ No response (NR) or answered I don't know (IDK)
} 
Table 5. Definitional types in different categories in form per group.

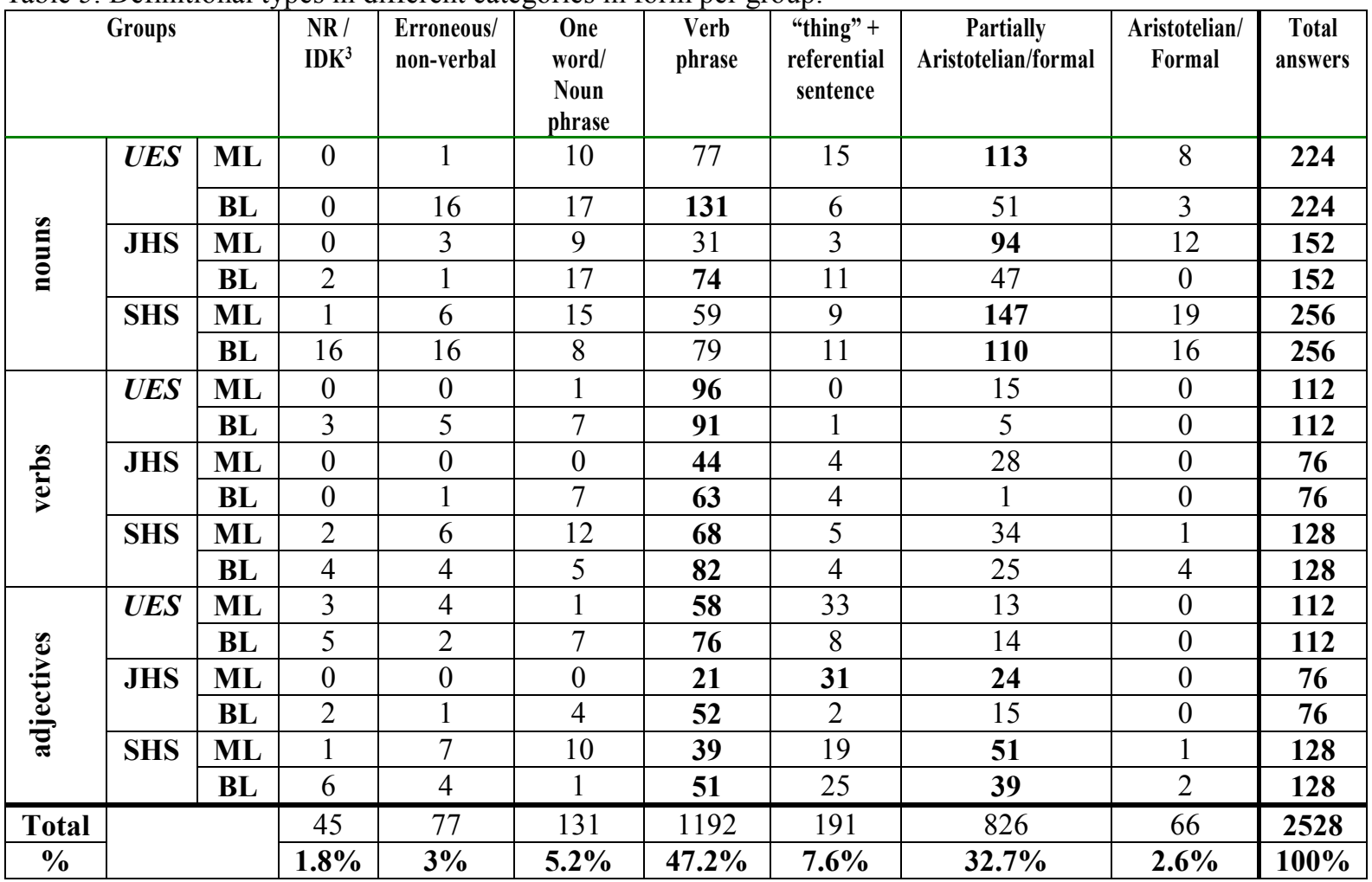

\section{Discussion}

The aim of the present study was to investigate, considering the level of students' education, (1) the definitional skills of Greek monolingual and Turkish-Greek bilingual students in content and form, (2) the effect of grammatical categories on their definitions and (3) the preferred definition types that they use.

Our hypotheses are discussed accordingly based on the research questions we set.

\subsection{Overall definitional abilities of monolingual and bilingual students}

Our first hypothesis was that bilingual students would produce better definitions, at least in form, since form involves metalinguistic skills; while in content, we hypothesized that bilinguals' performance would be lower than monolinguals, due to their lower language proficiency in Greek.

Our hypothesis was partially confirmed, since monolinguals outperformed bilinguals in both content and form, at least in upper elementary school and in junior high school. In senior high school, bilinguals seemed to catch up their monolingual peers in form and they reduced the difference in content. The elimination of difference in form may be due to higher metalinguistic abilities that bilingual students have developed, which conceivably aid them to produce better definitions (Snow et al., 1991; Lee, 2005; Kang, 2013). The lower scores in content were expected since in some cases bilinguals may not know the superordinate term or the more general category in order to use them (El Euch \& De Koninck, 2006). In a similar vein, bilinguals, due to their lower vocabulary, did not know some nouns (cf. Table 4), which were more abstract or compound. Nevertheless, the investigation of these parameters will be performed in a follow up study.

With-in differences have shown that content and form develop differently in monolinguals. Thus, monolinguals improve their skills in content in junior high school (Dourou, 2019; Dourou et al., 2020); while in form, the skills seem to remain stable across the three levels of education, suggesting that the skill has been already developed and it may improve in adulthood (Dourou et al., 2020). The only difference observed was between upper elementary and junior high students, where the difference could be incidental or the effect of an educational practice. On the other hand, bilinguals showed improvement in senior high school in both content and form. The finding points out that they possibly need more time to catch up.

The aforementioned findings further suggest that content is a more 'sensitive' index in the development of definitions than form (Kang, 2013; Dosi \& Gavriilidou, 2020).

\footnotetext{
${ }^{3}$ No response (NR) or answered I don't know (IDK)
} 


\subsection{The effect of grammatical category}

Our second hypothesis concerned grammatical categories. Hence, we hypothesized that monolinguals would outperform bilinguals in all grammatical categories, due to their vocabulary knowledge. Moreover, nouns would be better defined compared to adjectives and verbs. In addition, we assumed that both monolingual and bilingual junior and senior high school students would outperform upper elementary school students.

Our hypotheses were partially confirmed. Monolinguals outperformed bilinguals in all grammatical categories, in both content and form, albeit only in junior high school. This higher performance could be incidental or the result of a teaching intervention. However, it is important to note that monolingual and bilingual junior and senior high school students do not differ. Thus, we suggest that this outcome should be further investigated and discussed. Nevertheless, in the other two levels of education we observed differences between monolinguals and bilinguals. In upper elementary school, differences between the two language groups were found only in nouns and verbs, but not in adjectives, both in content and in form; while the difference in verbs disappeared in senior high school. The findings possibly suggest that verbs are more challenging than nouns and adjectives, since they establish a less hierarchical nature which hampers the activation of a class term in order to give a formal definition (Johnson \& Anglin, 1995; Friedmann et al., 2011; Gavriilidou, 2011, 2015; Dourou, 2019). Thus, formal definitions in verbs need time to improve, in both content and form. On the other hand, adjectives progress faster than verbs (Gertner, 1982; Graesser et al., 1987; Markman, 1989), but still similarly across the two groups (monolinguals and bilinguals), in both content and form. Based on previous studies this precedence of adjectives in comparison to verbs occurs since adjectives appeared to be dependent on nouns (Gavriilidou, 2015). Concerning nouns, the seemed to develop faster in monolinguals, possibly due to vocabulary knowledge and organization.

Interestingly, similar patterns were observed in the development of the content of grammatical categories within the two groups. More specifically, in nouns more formal definitions were used compared to verbs and adjectives by both groups across the three education levels, suggesting, as mentioned above, that the characters of nouns facilitate the use of superordinate categories (Nippold et al., 1999; Snow, 1990; Dourou, 2019). Adjectives and verbs did not differ in upper elementary students, but the difference emerged in junior high school (Dourou, 2019; Dourou, Gavriilidou \& Markos, 2020), indicating that initially verbs and adjectives are equally difficult to be defined, thus children use more informal definitions, but after the age of 12, definitions of adjectives become more formal; conceivably due to their characteristics, since adjectives describe aesthetic properties of nouns (Gavriilidou, 2015); however, verbs are still challenging and they receive more informal definitions (Johnson \& Anglin, 1995). In form, the patterns between monolinguals and bilinguals differ. Similar performance to content is observed in monolinguals; thus, nouns received more formal definitions compared to adjectives and verbs across the three levels of education and the difference between adjectives and verbs arose in junior high school (Benelli et al., 1988; Snow et al., 1991; Johnson \& Anglin, 1995; Nippold, 1995; Dourou, 2019). In bilinguals, adjectives and verbs follow the same pattern of development; hence the difference emerged in junior high school. By contrast, in bilinguals, nouns did not differ from adjectives in form across all the three education levels, possibly indicating that the advanced metalinguistic abilities compensate for word characteristics.

\subsection{Definitional types and grammatical categories}

Our last hypothesis concerned the definitional types that were used per grammatical category. We expected that junior and senior high school students would provide more formal definitions (in content and form) in comparison to upper elementary students. Moreover, we expected that bilingual students would produce high-level responses definitions in form, particularly in junior and senior high school, according to previous literature (Bialystok, 1986; Snow et al., 1991); while in content, we expected that bilinguals' performance would be lower (low- or mid-level responses) than monolinguals (high-level responses), due to their lower language proficiency in Greek.

Our hypotheses were not fully confirmed. Hence low-level definitions (functional or descriptive definitions) were used in verbs and adjectives in both content and form by all groups across all levels of education. As stated in Huttenlocher and Lui (1979), the use of superordinate terms is less clear in verbs. In the same line, Gentner (1982) and Miller (1991) insisted that verbs are difficult to define because they refer to activities, motion, changes of state, relations and all these reasons have an effect on the complexity of verbal definition production. Interestingly, we should remark that great divergence was detected in adjectives (form) in junior high school monolingual students; thus, they produced either low-, mid- or high-level responses. There is no previous research examining the ability of bilinguals to define verbs and adjectives. Low-level responses were attested in nouns in upper elementary monolingual and bilingual students. In addition, many of the monolingual upper elementary students used high-level responses in nouns. A similar performance is spotted in monolingual junior and senior high school students and only in bilingual senior high students; thus, they used high-level responses in nouns (partially formal definitions). The same pattern was also observed in form, further proofing that it more likely for the nouns to be better defined (Benelli et al., 1988; Nippold et al., 1999; Snow, 1990; Dourou, 2019). 


\section{Conclusions, limitations of the study and further research}

Our study offers new insights on the study of the development of definitional skills in monolingual and bilingual students. Monolinguals provided more formal definitions compared to bilinguals; conceivably since the bilingual group of our study had lower vocabulary knowledge. Nevertheless, the difference between the groups dissipated in form of definitions in senior high school; conceivably due to the enhanced metalinguistic abilities that form of definitions requires, bilingual speakers manage to catch up their monolingual peers. This finding further evidenced that content is the most 'sensitive' indicator, since differences in content did not disappear. Nouns received more formal definitions compared to verbs and adjectives; while the difference between adjectives and verbs, emerged in junior high school, in all groups. The outcomes suggested that the development of definitional skills in bilinguals follows quite similar patterns to this of monolinguals; however, it needs more time to improve in bilinguals.

On account of this, educators can work on the enhancement of the bilingual mental lexicon organization in both languages in order to further support the definitional abilities in different words of their bilingual students, considering the effects and interactions of word characteristics and students' level of education.

Some limitations of the study should be acknowledged. First, our bilingual group consisted of Turkish dominant bilinguals and even though the group was uniform, having not tested balanced or Greek dominant bilinguals, we cannot overgeneralize our findings. Second, we did not test them in respect to their definitional skills in Turkish. Future studies can work to this direction. A final limitation was that we did not analyzed the results based on their semantic characteristics (i.e. abstract vs. concrete words) and morphological structure (i.e. simple/derived and compound words). Nevertheless, these are analyses that we intend to perform in a follow up study.

Future research can work on the investigation of more word characteristics. For instance, the effect of word structure and semantic characteristics on definitional skills and definitional types used by monolingual and bilingual students. In addition, follow-up studies can investigate balanced bilinguals in order to spot whether similar results are exhibited. Finally, of great importance would be the investigation of bilinguals' definitional skills in both languages.

All in all, we expect that our paper adds value to the existing work on bilingual definitional skills, by investigating less-researched parameters, particularly concerning the development of bilinguals' definitional skills. It is hoped that this study provides an enhanced understanding of how monolingual and bilingual students define words and that this research-based knowledge can be employed in helping teachers to expand their perspectives on good teaching of Greek as foreign or second language.

\section{References}

Benelli, B., Arcuri, L., \& Marchesini, G. (1988). Cognitive and linguistic factors in the development of word definitions. Journal of Child Language, 15(3), 619-635. https://doi.org/10.1017/S0305000900012599

Benelli, B., Belacchi C., Gini, G., \& Lucangeli, D. (2006). To define means to say what you know about thing: The development of definitional skills as metalinguistic acquisition. Child Language, 33(1), 71-97. https://doi.org/10.1017/S0305000905007312

Caramelli, N., Borghi, A. M., \& Setti, A. (2006). The identification of definition strategies in children of different ages. Linguistica Computazionale, 26, 155-178. https://doi.org/10.1400/59033

Chan, Y.L., \& Marinellie, S.A. (2007). Definitions of idioms in preadolescents, adolescents and adults. Journal of Psycholinguistic Research, 37, 1-20.

Colombo, G., Henrion, R., Hoang, N.D, \& Mor-dukhovich, B.Sh. (2016). Optimal control of the sweeping process over polyhedral controlled sets. J. Differential Equations, 260, pp. 3397-3447.

Cummins, J. (1976). The influence of bilingualism on cognitive growth a synthesis of research findings and explanatory hypotheses. Working Papers on Bilingualism, 9, 1-43.

Cummins, J. (1979). Linguistic interdependence and the educational development of bilingual children. Review of Educational Research, 49, 222-251. https://doi.org/10.3102/00346543049002222

Dosi, I. (2020). Enhancing formal word definitions: an educational intervention plan for monolingual \& bilingual children. Journal of Innovation in Psychology, Education and Didactics 24(2), 1-17.

Dosi, I., Gavriilidou, Z. (2020). The Role of Cognitive Abilities in the Development of Definitions by Children with and Without Developmental Language Disorder. Journal of Psycholinguistic Research, 49(5), 761-777. https://doi.org/10.1007/s10936-020-09711-w

Dosi, I., Gavriilidou Z. \& Dourou, C. (in press). Definitional abilities of elementary students with and without Developmental Language Disorder. Journal of Communication Disorders.

Dourou, C. (2019). The comparison of definition ability of different age groups. (Unpublished doctoral dissertation). Department of Greek Philology. Democritus University of Thrace. [In Greek].

Dourou, C., Gavriilidou, Z., \& Markos, A. (2020). Definitional skills and preferred definition types according to age, gender, educational level and career orientation. International Journal of Research Studies in Education, 9(2), 29-49. https://doi.org/10.5861/ijrse.2020.5021. 
El Euch, S. (2007) Concreteness and Language Effects in the Quality of Written Definitions in L1, L2 and L3, International Journal of Multilingualism, 4(3), 198-216, DOI: 10.2167/ijm071.0

El Euch, S. et De Koninck, Z. (2006). Habiletés de décontextualisation en situation trilingue: le cas des définitions. La Revue Canadienne de Linguistique Appliquée, 9(1), 13-30.

Friedmann, N., Aram, D., \& Novogrodsky, R. (2011). Definitions as a window to the acquisition of relative clauses. Applied Psycholinguistics, 32(4), 687-710. https://doi.org/10.1017/S0142716411000026

Gavriilidou, Z. (2011). The development of word definitions in Greek Preschoolers, In K. Chatzopoulou, A. Ioannidou, \& Y. Suwon (Eds.) Proceedings of the 9th I.C.G.L. (pp. 88-96).

Gavriilidou, Z. (2015). The development of noun, verb and adjective definitional awareness in Greek preschoolers, Journal of Applied Linguistics, 30, 44-58.

Johnson, C. J., \& Anglin, J. M. (1995). Qualitative developments in the content and form of children's definitions. Journal of Speech and Hearing Research, 38(3), 612-629. https://doi.org/10.1044/jshr.3803.612

Kang, J. (2013). Decontextualized language production in two languages: An investigation of children's word definition skills in Korean and English. Applied Psycholinguistics, 34(2), 211-231. https://doi.org/10.1017/S0142716411000671

Kurland, B. F., \& Snow, C. (1997). Longitudinal measurement of growth in definitional skill. Journal of Child Language, 24, 603-26. https://doi.org/10.1017/S0305000997003243

Lee, I. (2005). Study of definition skills of concrete nouns of Korean-English bilingual children. Unpublished master's thesis, Myongji University.

Malakoff, M. (1988) The effect of language of instruction on reasoning in bilingual children. Applied Psycholinguistics 9 (1), 1738.

Marinellie, S. (2010). Improving children's formal word definitions: A feasibility study. Child Language Teaching and Therapy, 26 (I), 23-37.

Marinellie, S. A., \& Johnson C. (2002). Definitional skill in school-age children with specific language impairment. Journal of Communication Disorders, 35(3), 241-259. https://doi.org/10.1016/S0021-9924(02)00056-4

Marinellie, S. A., \& Johnson, C. (2003). Adjective definitions and the influence of word frequency. Journal of Speech, Language \& Hearing Research, 46(5), 1061-76. https://doi.org/10.1044/1092-4388(2003/084)

Marinellie, S. A., \& Johnson C. (2004). Nouns and Verbs: a comparison of definitional style. Journal of Psycholinguistic Research, 33(3), 217-235. https://doi.org/10.1023/B:JOPR.0000027963.80639.88.

Markowitz, J., \& Franz, S. (1988). The development of defining style. International Journal of Lexicography, 1(3), 253-267. https://doi.org/10.1093/ijl/1.3.253

McGhee-Bidlack, B. (1991). The development of noun definitions: a metalinguistic analysis. Journal of Child Language, 18(2), 417-434. https://doi.org/10.1017/S0305000900011132

Nippold, M. A. (1995). School-age children and adolescents: Norms for word definitions. Language, Speech and Hearing services in Schools, 26, 320-325.

Nippold, M. A., Hegel, S., Sohlberg, M. M., \& Schwarz, I. (1999). Defining abstract entities: Development in preadolescents, adolescents, and young adults. Journal of Speech, Language, and Hearing Research, 42, 473481. https://doi.org/10.1044/jslhr.4202.473

Ordonez, C., Carlo, M., Snow, C., \& McLaughlin, B. (2002). Depth and breadth of vocabulary in two languages: Which vocabulary skills transfer? Journal of Educational Psychology, 94, 719-728. https://doi.org/10.1037//0022-0663.94.4.719

Pham G, Donovan D, Dam Q, Contant A. (2018). Learning Words and Definitions in Two Languages: What Promotes Cross-Language Transfer? Lang Learn. 68(1): 206-223.

Sadoski, M., Kealy, W. A., Goetz, E. T., \& Paivio, A. (1997). Concreteness and imagery effects in the written composition of definitions. Journal of Educational Psychology, 89, 518-526.

Snow, C. E. (1990). The development of definitional skill. Journal of Child Language, 17(3), 697-710. https://doi.org/10.1017/S0305000900010953

Snow, C.E., Cancino, H., De Temple, J., \& Schley, S. (1991). Giving formal definitions: A linguistic or metalinguistic skill? In E. Bialystok (Ed.), Language processing in bilingual children (pp. 90-111). Cambridge: Cambridge University Press.

To, C. K. S., Stokes, S., Man, Y., \& T'sou, B. (2013). An Analysis of Noun Definition in Cantonese. Language and Speech, 56(1), 105-124. https://doi.org/10.1177/0023830912440794

Watson, R. (1985). Towards a theory of definition. Journal of Child Language, 12(1), 181-197. https://doi.org/10.1017/S0305000900006309

Wehren, A., De Lisi, R., \& Arnold, M. (1981). The development of noun definition. Journal of Child Language, 8(1), 165-175. https://doi.org/10.1017/S0305000900003081 